\title{
Correction: Telomere length-dependent transcription and epigenetic modifications in promoters remote from telomere ends
}

\author{
Ananda Kishore Mukherjee, Shalu Sharma, Suman Sengupta, Dhurjhoti Saha, \\ Pankaj Kumar, Tabish Hussain, Vivek Srivastava, Sumitabho Deb Roy, Jerry W. Shay, \\ Shantanu Chowdhury
}

There is an error in affiliation 2 for authors Ananda Kishore Mukherjee, Shalu Sharma, Pankaj Kumar and Shantanu Chowdhury. The correct affiliation 2 is: Academy of Scientific and Innovative Research (AcSIR), Ghaziabad-201002, India.

\section{Reference}

1. Mukherjee AK, Sharma S, Sengupta S, Saha D, Kumar P, Hussain T, et al. (2018) Telomere lengthdependent transcription and epigenetic modifications in promoters remote from telomere ends. PLoS Genet 14(11): e1007782. https://doi.org/10.1371/journal.pgen.1007782 PMID: 30439955

Citation: Mukherjee AK, Sharma S, Sengupta S, Saha D, Kumar P, Hussain T, et al. (2020)

Correction: Telomere length-dependent transcription and epigenetic modifications in promoters remote from telomere ends. PLoS Genet 16(10): e1009152. https://doi.org/10.1371/ journal.pgen.1009152

Published: October 22, 2020

Copyright: ๑ 2020 Mukherjee et al. This is an open access article distributed under the terms of the Creative Commons Attribution License, which permits unrestricted use, distribution, and reproduction in any medium, provided the original author and source are credited. 